\title{
CONTROL, PREVENCIÓN Y REPRESIÓN ANTE EL LAVADO DE ACTIVOS EN EL PERÚ
}

\author{
CONTROL, PREVENTION AND REPRESSION AGAINST \\ MONEY LAUNDERING IN PERU
}

\section{JERI GLORIa Ramón RUfFNER*}

Docente Principal de la Facultad de Ciencias Contables, UNMSM

[Recepción: Abril de 2011/ Conformidad: mayo de 2011]

\section{RESUMEN}

El artículo que se desarrolla en esta oportunidad busca desarrollar de manera dinámica y amplia el tema del Control, Prevención y represión del lavado de activos en el Perú: así mismo determinar sus efectos a la crisis económica nacional y financiera .Para ello el proyecto evaluará tres perspectivas desde el ámbito del Marco Legal Internacional y Nacional, Delito de lavado de activos y delitos vinculados, así como el tratamiento en la legislación peruana y legislación comparada. Se interpretará además la Ley que estableció la obligatoriedad para las instituciones financieras inspeccionadas de implementar mecanismos de prevención, orientados a evitar la canalización de recursos de origen ilícito a través de sus operaciones y el compromiso de la Superintendencia Financiera, como órgano supervisor del Estado, de verificar la funcionalidad, idoneidad y efectividad de esos mecanismos.

El artículo no sólo busca remarcar la actual regulación del lavado de dinero o de activos en el Perú, sino también evidenciar apreciables defectos de técnica legislativa y de enfoque político, llegando a proponer ciertas medidas para una mejor ejecución ante la aplicación de notorias omisiones en lo relativo a disposiciones complementarias de control extrapenal.

Si de la evaluación y análisis de los resultados de la investigación determinamos que estos sistemas de control interno de las diversas

\begin{abstract}
The article is developed at this time seeking to develop dynamically and extends the theme of control, prevention and suppression of money laundering in Peru: it can also determine their effects on national economic and financial crisis. This project will evaluate three perspectives from the field of International Legal Framework and National Crime money laundering and related offenses, and treatment under Peruvian law and comparative law.

It also interpreted the law that established the requirement for audited financial institutions to implement prevention mechanisms, oriented to avoid channeling funds of illicit origin through its operations and its commitment to the Financial Supervisory Authority as supervisor of the State, verify the functionality, appropriateness and effectiveness of these mechanisms.

The article not only seeks to highlight the current regulation of laundering money or assets in Peru, but also demonstrate significant technical defects of legislative and policy approach, leading to propose some measures for better performance to the application of notable omissions in Additional provisions relating to parole control. If the assessment and analysis of the results of the investigation determined that these internal control systems of the various regulatory bodies are not capable of understanding the integral control, we propose a mo-
\end{abstract}

* Doctora en Contabilidad, Magister en Anticorrupción, Docente Principal de la Facultad de Ciencias Contables - UNMSM, Docente Investigadora - UNMSM. E-mail: jeriramon_162@hotmail.com 
entidades regulatorias no son capaces de concebir el control integral, propondremos un modelo de sistema de control, con su respectiva metodología de implantación que busque aplicar un control de advertencia o de prevención en los diferentes niveles organizacionales ante el lavado de activos.

Palabras clave: Lavado de activos, Sistemas de control, Modelo GAFI, Política Global de fiscalización.

\section{INTRODUCCIÓN}

El artículo que se desarrolla en esta oportunidad busca desarrollar de manera dinámica y amplia el tema del Control, Prevención y represión del lavado de activos en el Perú: así mismo determinar sus efectos a la crisis económica nacional y financiera .Para ello el proyecto evaluará tres perspectivas desde el ámbito del Marco Legal Internacional y Nacional, Delito de lavado de activos y delitos vinculados, así como el tratamiento en la legislación peruana y legislación comparada.

Se interpretará además la Ley que estableció la obligatoriedad para las instituciones financieras inspeccionadas de implementar mecanismos de prevención, orientados a evitar la canalización de recursos de origen ilícito a través de sus operaciones y el compromiso de la Superintendencia Financiera, como órgano supervisor del Estado, de verificar la funcionalidad, idoneidad y efectividad de esos mecanismos.

El artículo no sólo busca remarcar la actual regulación del lavado de dinero o de activos en el Perú, sino también evidenciar apreciables defectos de técnica legislativa y de enfoque político, llegando a proponer ciertas medidas para una mejor ejecución ante la aplicación de notorias omisiones en lo relativo a disposiciones complementarias de control extrapenal.

\begin{abstract}
del of control system, with their respective implementation methodology that seeks to implement control warning or prevention at different organizational levels to money laundering.
\end{abstract}

Key words: Money laundering, control systems, Model GAFI, Global audit policy.

Si de la evaluación y análisis de los resultados de la investigación determinamos que estos sistemas de control interno de las diversas entidades regulatorias no son capaces de concebir el control integral, propondremos un modelo de sistema de control, con su respectiva metodología de implantación que busque aplicar un control de advertencia o de prevención en los diferentes niveles organizacionales ante el lavado de activos.

\section{LAVADO DE DINERO: ("Money laun- dering")}

Constituye una colosal infracción financiera contemporánea. Ordinariamente se supone que el delincuente que amasa fortunas mal habidas es un "lavador" de dinero, pero está claro que no es así. Lavar dinero significa "limpiarle la cara" al patrimonio espurio y poder justificarlo durante el examen de un auditor severo y entendido. De ello, se entiende que El lavado de dinero, es la legitimación del dinero circulante obtenido de fuentes ilícitas (Tráfico Ilícito de Drogas), mediante su introducción en la economía de los países, ya sea a través del Sistema Financiero o Bancario o su inversión en los campos de exportación, importación o compra de bienes raíces, para mezclarlo con el flujo monetario legítimo y hacerlo aparecer como fuente legal. 
El Lavado o llamado también Blanqueo de dinero procedente del tráfico ilícito de drogas es la forma o manera que tienen los delincuentes de justificar sus ingresos ilícitos y hacerlos aparecer como lícitos, para lo cual se valen de una serie de mecanismos en las inversiones del dinero a través de la banca, dándole una apariencia legal.

\section{DIVERSAS DENOMINACIONES}

- Argentina: Lavado de Activos

- Bolivia: Legitimación de ganancias ilícitas

- Brasil: Lavado de Bienes, Derechos y Valores

- Chile: Lavado de Dinero

- Colombia: Lavado de Activos

- Ecuador: Conversión o transformación de bienes (Lavado de Dinero).

- México: Operaciones con recursos de procedencia ilícita.

- Panamá: Blanqueo de Capitales

- Paraguay: Lavado de Dinero o Bienes

- Perú: Lavado de Activos

- Uruguay: Blanqueo de Dinero

- Venezuela: Legitimación de Capitales.

\section{CARACTERÍSTICAS}

a) Es un delito de guante blanco.- El lavado de dinero implica operaciones financieras cuantiosas que le dan al lavador la posición económica privilegiada.

b) Es un conjunto de operaciones complejas.- Muchas de las operaciones del lavado de dinero tienen características, frecuencias o volúmenes que se salen de los parámetros habituales, o se realizan sin un sentido económico.

c) Es el fenómeno de dimensiones internacionales.- El desarrollo tecnológico de los canales financieros mundiales facilita a la delincuencia organizada operar en el ámbito nacional e internacional.

d) Se sirve de los avances tecnológicos y la vulnerabilidad del sector financiero.- El alto volumen y la rapidez con que se hacen las operaciones, ya que los avances tecnológicos facilitan la realización de operaciones financieras a partir de simple asientos contables o registros electrónicos, lo hacen vulnerables.

\section{MECANISMO DEL LAVADO DE DINERO:}

Un mecanismo de lavado de dinero es una empresa comercial o financiera que facilita el lavado. Muchas de las empresas financieras (ejemplo: bancos o casas de cambio) participan en negocios legítimos también toman parte a sabiendas o sin saber, en el lavado de fondos ilegales.

Algunos de los mecanismos más comunes de lavado de dinero son:

- Negocios supuestamente legales, que sobrevalúen sus ingresos para esconder dinero ilícito, aun cuando tengan que pagar más impuesto.

- Casinos, obteniendo certificados en casas de juego donde se justifiquen la ganancia de grandes cantidades de dinero.

- Giros al exterior, utilizando las casas de giro para movilizar dinero entre países, aprovechando la falta de controles, caso "Los norteños".

- Autopréstamos, creando empresas financieras de fachada, la cual otorgaría préstamos a traficantes con su propio dinero, caso concreto de una entidad ubicada en el oriente peruano. Modalidad muy usada en Colombia.

- Préstamos ficticios, armando una operación inexistente con bancos extranjeros, 
que prestan grandes cantidades de dinero, generalmente para el apoyo agropecuario.

- Casas de Cambio, cambiando la moneda por certificados de cambio mucho más fáciles de ser trasladados sin ninguna sospecha

- Sobrefacturación de exportaciones, inflar los montos exportados para justificar una mayor cantidad de divisas recibidas.

- Zonas de libre comercio, aprovechando la falta de controles para realizar operaciones comerciales con dinero "sucio".

- Exportaciones ficticias, simular operaciones de comercio exterior, generalmente en la pesca.

- Activos, sobrevalorar una empresa al comprarla o venderla, especialmente las empresas pesqueras.

- Operaciones bursátiles, adquirir valores de alguna empresa, generalmente de prestigio, para incrementar su patrimonio.

- Inversiones en bienes raíces, comprar o vender propiedades, sobrevaloradas o difíciles de valorar, por ejemplo las propiedades haciendas de Tito López Paredes.

- Comercialización de joyas, obras de arte, antigüedades, sobrevaluadas, para poder movilizar grandes cantidades de dinero, generalmente al exterior con una sola transacción.

- Financiamiento de campañas políticas, especialmente se encuentra esta modalidad en las famosas donaciones de grandes capitalistas, empresarios que prestan para actuar como testaferros.

- Constitución de entidades de servicio público y fundaciones acogiéndose especialmente a la confianza, aprovechando ser visto con las altas autoridades, para luego recurrir a exoneraciones de tributos $\mathrm{u}$ otros.

\section{ETAPAS DE LAVADO DE ACTIVOS}

\section{MODELO DEL GAFI:}

- Primera Etapa: Colocación de los bienes o del dinero en efectivo

- Segunda Etapa: Fraccionamiento o transformación

- Tercera Etapa: Inversión, integración o goce de los capitales ilícitos ( es la finalización del proceso).

\section{MODELO DE BERNASCONI O MODE- LO DE FASE}

- En Primer Grado: La denomina MONEY LAUDERING, es decir conjunto de actuaciones con las cuales en el corto plazo se liberan los bienes contaminados.

- En Segundo Grado: RECYCLING se refiere a las operaciones a mediano y largo plazo de bienes ya lavados que son posteriormente utilizados para lograr una desconexión absoluta del delito previo.

\section{MODELO DE ZUND O MODELO DEL CICLO DEL AGUA:}

- Precipitación: Producción del dinero o billete originado en el delito previo.

- Infiltración: El dinero recogido por la organización criminal es sometido a una primera fase de lavado transformándolo, por ejemplo en billetes de alta denominación.

- Corriente de Aguas Subterráneas: El dinero se convierte en otras formas patrimoniales.

- Desagüe: El dinero es entregado a otra área de la organización o atrás para proceder a la realización de transferencias normalmente al exterior.

- Nueva Acumulación y Estación de Bombeo: El dinero es nuevamente recibido por la organización y se destina a la apertura de cuentas en entidades financieras. 
- Estación de Depuración y Aprovechamiento: Se utilizan testaferros y se mueven los dineros de cuenta en cuenta para encubrir rastros criminales.

- Evaporación y Precipitación: El dinero lavado cuyo rastro legal ha sido borrado (evaporado) es destinado nuevamente a actividades criminales o utilizado para el goce del delincuente.

\section{MODELO DE FINCEN (Departamento del Tesoro):}

- Comienza con la producción de la riqueza generada por los delitos graves.

- Posteriormente se introducen a la economía legal, donde se reagrupan y reinvierten en actividades ilegales o legales.

\section{MODELO TELEOLÓGICO (AUTOR SUIZO ACKERMAN):}

- Se inspira en los objetivos de las etapas de lavado:

- Principales: Evitar el decomiso o confiscación de los bienes y asegurar su disfrute (ocultación física de los activos).

- Secundarios: Confusión de los activos con otros de origen legal.

- Complementarios: Evitar el juzgamiento de los autores del delito previo.

\section{DETERMINACIÓN DE LA PRE- SUNCIÓN DEL DELITO}

Está constituida por aquella actividad que han de desarrollar las partes acusadoras ante el Juzgador con el objeto de desvirtuar la presunción de inocencia

a) Cuestiones esenciales:

- Determinación del origen criminal

- Conocimiento del origen ilícito

b) determinación del origen criminal :

- Delito autónomo e independiente: la prueba del delito antecedente puede practicarse y obtenerse en el mismo proceso iniciado por el delito de lavado

- No requiere la identificación de un acto delictivo concreto como antecedente

- No es necesaria la existencia de un procedimiento judicial previo por el delito antecedente

- No exige la previa condena por el delito del que proceden los bienes

c) Circunstancias Demostrativas del Origen

Criminal:

- Vinculación con investigaciones criminales

- Comisos de droga u otros efectos delictivos

- Sujeción a procedimientos judiciales por actividades delictivas

- Contenido de conversaciones telefónicas

- Ausencia de negocios lícitos que justifiquen las operaciones o incrementos

- Documentación sobre contabilidades de operaciones clandestinas o relacionada con posibles operaciones criminales (mapas, coordenadas de punto de encuentro de buques, claves para comunicaciones por radio, etc)

d) Elementos:

- Incrementos patrimoniales injustificados u operaciones financieras anómalas

- Inexistencia de actividades económicas o comerciales legales

- Vinculación o conexión con actividades ilícitas como consideradas como delito base

\section{EL LAVADO DE ACTIVOS EN EL PERÙ}

Realizando una síntesis se puede determinar el origen y desarrollo en cuanto al procedimiento penal de la lucha ante el lavado de activos en el Perú: 
a) En el Perú existe desde 1992, bajo el nombre de LAVADO DE DINERO

b) Entro en vigencia por Decreto Ley $25428(11 / 04 / 92)$ que incorporó tal delito en el art. 296-B del Código Penal : sólo existía cuando las ganancias o bienes de una persona o empresa provenían del trafico de drogas (delito precedente); es decir que para que se configure, se requería la presencia de dos elementos como mínimo: ganancias que presuntamente no pueden justificarse con actividades licitas o legales y que esta persona o empresa cuente con alguna referencia, nota de inteligencia, Investigación o proceso por tráfico de drogas, de manera que tal incremento patrimonial no justificado pueda porvenir de este último delito

c) Con la promulgación de Ley No 27765 (27/06/02), se derogó expresamente el art. 296 - B del Código Penal, y se cambio su nomenclatura a LAVADO DE ACTIVOS, considerando ya no solo a TID como único delito precedente, sino a todos, salvo las excepciones sindicadas en su art. $6^{\circ}$, porque si bien se indica expresamente cuales serian los delitos precedentes, al final de tal enumeración agrega "..y todos aquellos generen ganancias ilegales...”, siendo por ello considerada como una cláusula abierta para que el Fiscal o juez evalúen la idoneidad de la referencia delictiva para generar ganancias.

d) La Ley Na 27765 solo ha tenido dos modificación la Ley No 28355 (06/10/04), el art. $3^{\circ}$ y $7^{\circ}$, y el Decreto Legislativo No. 986 (21/07/07): siendo los artículos modificados los siguientes: $1^{\circ}, 2^{\circ}, 3^{\circ}$, $4^{\circ}$ y $6^{\circ}$

e) Ley No 2776527 de junio del 2002 LEY PENAL CONTRA EL LAVADO DE ACTIVOS
Ley No 28355 / Decreto Legislativo No 986

\section{MORFOLOGÍA Y CONTENIDO ESPE-} CÍFICO DEL TIPO PENAL

- Actos de Conversión y Transferencia ( art.1)

- Actos de Ocultamiento y Tenencia (art.2)

- Circunstancias Agravantes (art. 3)

- Omisión de Reportes de Operaciones o Transacciones Sospechosas (art. 4)

- Reglas sobre el Levantamiento del Secreto Bancario y la Reserva Tributarias y Bursátil (art. 5).

- Empleo de la Prueba Indiciaria (art. 6) .

- Beneficios penitenciarios (art. 7).

\section{ACTOS DE CONVERSIÓN Y TRANS- FERENCIA}

- Artículo 01\%.- El que convierte o transfiere dinero, bienes, efectos o ganancias cuyo origen ilícito conoce o puede presumir, y dificulta la identificación de su origen, su incautación o decomiso, será reprimido con pena privativa de la libertad no menor de 08 ni mayor de 15 años y con 120 a 350 días multa

\section{ACTOS DE OCULTAMIENTO Y TE- NENCIA}

Artículo 020.- El que adquiere, utiliza, guarda, custodia, recibe, oculta, administra o transporta dentro del territorio de la República o introduce o retira del mismo o mantiene en su poder dinero, bienes, efectos o ganancias, cuyo origen ilícito conoce o puede presumir, y dificulta la identificación de su origen, su incautación o decomiso, será reprimido con pena privativa de la libertad no menor de ocho ni mayor de quince años y con ciento veinte a trescientos cincuenta días multa." 


\section{FORMAS AGRAVADAS:}

Artículo 03 La PPPL será no menor de 10 ni mayor de 20 años y 365 a 730 días multa, cuando:

a) El agente utilice o se sirva de su condición de funcionario público o de agente del sector inmobiliario, financiero, bancario o bursátil.

b) El agente comete el delito en calidad de integrante de una organización criminal.

La pena será privativa de la libertad no menor de 25 años cuando los actos de conversión y transferencia o de ocultamiento y tenencia se relacionen con dinero, bienes, efectos o ganancias provenientes del tráfico ilícito de drogas, terrorismo, secuestro, extorsión, trata de personas o delitos contra el patrimonio cultural, previsto en los artículos 228 y 230 del Código Penal."

- Inciso A) del Artículo 3o de la Ley.-

* Por la calidad del sujeto activo funcionario público: por su condición, cargo u oficio vinculado a la Administración Pública se sirva de ella para facilitar o favorecer el lavado de activos

* Se basa en la infracción de deberes y de las competencias institucionales que todo funcionario público detenta respecto a la Administración Pública, $y$ en la facilidad que tiene para favorecer el delito y garantizar la impunidad desde el cargo o la función que ocupa. - Concordado con el art. $425^{\circ}$ del C.P. - funcionario público (agente de la administración que ejerce la función pública, teniendo por ello capacidad de decisión y representación, tanto al interior de la administración como al exterior de la entidad a la que pertenece - frente a terceros)

* Se excluye a los servidores públicos (contribuyente del ejercicio de la fun- ción pública ejercida por funcionario público)

* Por la calidad del sujeto activo en el sector inmobiliario, financiero, bancario o bursátil: atendiendo a su especial posición o manejo de actividades cercanas e inmediatas al lavado de activos - relación material: se exige la práctica regular y continua de cualquiera de las actividades y sectores enunciados en la Ley

- Inciso B) del Artículo 3o de la Ley.-

* Forma como el hecho es cometido: Organización, deriva de la existencia de ente con carácter de institución y que posee las notas de permanencia y regularidad en el tiempo, no dependiendo de la permanencia de sus miembros, sino que ella implique la alteración o fungibilidad de la institución

* Una organización criminal supone una determinación clara y definida de los objetivos a alcanzar y una adecuada selección de los medios y procedimientos, para lo cual se dispone una distribución de funciones (formal o material) y un necesario principio jerárquico (mando, toma de decisiones y ejecución)

* Basta que la organización tenga un carácter material en el que $\mathrm{c} / \mathrm{u}$ de sus miembros sepa sus funciones.

* Coexiste con una disciplina corporativa: sometimiento y aceptación del asociado, generado por un acuerdo o pacto común entre ellos (expreso o tácito)

* A aquellos que actúan a favor de la organización criminal y no forman parte de ella (socios,), son considerados cómplices

* El concepto de organización criminal se equipara, en sentido genérico, al de asociación ilícita. 
- Inciso C) del Artículo 3o de la Ley.-

* Referida al delito del cual provienen los activos materia del lavado: Tráfico Ilícito de Drogas o Terrorismo

* Antes de la modificación dada por la Ley No 28355 , se consideraba como un supuesto adicional el llamado narcoterrorismo, lo cual resultaba inadecuado porque no hay un tipo penal especifico con este nombre y porque cualquier acto que podía comprenderse en éste ya estaba comprendido en cualquiera de los dos delitos mencionados.

\section{OMISIÓN DE COMUNICACIÓN DE OPERACIONES O TRANSACCIONES SOSPECHOSAS:}

Artículo 04\%.- El que incumpliendo sus obligaciones funcionales o profesionales, omite comunicar a la autoridad competente, las transacciones u operaciones sospechosas que hubiere detectado, según las leyes y normas reglamentarias, será reprimido con pena privativa de la libertad no menor de cuatro ni mayor de ocho años, con ciento veinte a doscientos cincuenta días multa, e inhabilitación no mayor de seis años, de conformidad con los incisos 1), 2) y 4) del Artículo 36 del Código Penal."

\section{- Tipo Objetivo}

* Bien Jurídico.- funcionalidad de la Administración Pública, por ser delito de mera desobediencia

* Sujeto Activo.- Los funcionarios Públicos, y los profesionales, quienes por imperio de la ley o de sus reglamentos tienen el deber de garantizar de que en el ámbito de sus labores profesionales no se realicen acciones de lavado
Sujeto Pasivo.- Estado

* Comportamiento Típico.- infracción de deberes impuestos por el ordenamiento jurídico, el sujeto debe de encontrarse en la posibilidad de cumplir el deber impuesto , en donde no es necesario que las operaciones sospechosas sean efectivamente ilícitas, basta con la no comunicación a la autoridad competente de la misma

\section{- Tipo Subjetivo:}

* DOLO: Es suficiente que conozca o que se haya dado cuenta de que la operación o transacción es sospechosa (según la Ley No 27693)

\section{REGLAS DE INVESTIGACIÓN}

Artículo 050 .- Para la investigación de los delitos previstos en esta ley, se podrá levantar el secreto bancario, la reserva tributaria y la reserva bursátil, por disposición de la autoridad judicial o a solicitud del Fiscal de la Nación. La información obtenida en estos casos sólo será utilizada en relación con la investigación de los hechos que la motivaron.

\section{DISPOSICIÓN COMÚN}

Artículo 06.- El origen ilícito que conoce o puede presumir el agente del delito podrá inferirse de los indicios concurrentes en cada caso.

El conocimiento del origen ilícito que debe conocer o presumir el agente de los delitos que contempla la presente ley, corresponde a conductas punibles en la legislación penal como el tráfico ilícito de drogas; terrorismo; delitos contra la administración pública; secuestro; extorsión; proxenetismo; trata de personas; tráfico ilícito de migrantes; defraudación tributaria; contra el patrimonio en su modalidad agravada; delitos aduane- 
ros, $\mathrm{u}$ otros similares que generen ganancias ilegales, con excepción de los actos contemplados en el artículo 194 del Código Penal.

En los delitos materia de la presente ley, no es necesario que las actividades ilícitas que produjeron el dinero, los bienes, efectos o ganancias, se encuentren sometidas a investigación, proceso judicial o hayan sido objeto de sentencia condenatoria.

También podrá ser sujeto de investigación por el delito de lavado de activos, quien realizó las actividades ilícitas generadoras del dinero, bienes, efectos o ganancias".

\section{PROHIBICIÓN DE BENEFICIO PENI- TENCIARIO}

Artículo 07.- Los sentenciados por el delito previsto en último párrafo del Artículo 3 de la presente Ley no podrán acogerse a los beneficios penitenciarios de redención de la pena por el trabajo y la educación, semilibertad y liberación condicional.

\section{Ley No 28355 del 6 de octubre de 2004}

Ley que modifica diversos artículos del código penal y de la ley penal contra el lavado de activos:

- Artículo 3170.- Asociación Ilícita

- Artículo 393\%.- Cohecho pasivo propio.

- Artículo 394\%.- Cohecho pasivo impropio.

- Artículo 395\%.- Cohecho pasivo específico.

- Artículo 3960.- Corrupción pasiva de auxiliares jurisdiccionales antes.

- Artículo 397\%.- Cohecho activo genérico.

- Artículo 398\%.- Cohecho activo específico:

"El que, bajo cualquier modalidad, ofrece, da o promete donativo, ventaja o beneficio a un Magistrado, Fiscal, Perito, Árbitro, Miembro de Tribunal Administrativo o análogo con el objeto de influir en la decisión de un asunto sometido a su conocimiento o competencia, será reprimido con pena privativa de libertad no menor de cinco ni mayor de ocho años e inhabilitación accesoria."

Artículo 399․- Negociación incompatible o aprovechamiento indebido de cargo.

Artículo $400^{\circ}$.- Tráfico de influencias.Artículo 401ㅇ.- Enriquecimiento ilícito.

Artículo 401‥- Enriquecimiento ilícito

\section{Ley 2005-13 del 18 de octubre de 2005}

Que es necesario legislar con la finalidad de tipificar, en forma adecuada, las infracciones que tienen relación con la conversión o transferencia de activos provenientes de actividades ilícitas y de recuperarlos.

\section{SUJETOS OBLIGADOS BAJO SUPER- VISIÓN DE LA UIF.PERÚ- LEY No 29038 \\ RESOLUCION SBS No 496-.2008 de fecha 5 de marzo de 2008}

- Los administradores de bienes, empresas y consorcios.

- Las empresas o las personas naturales dedicadas a la compraventa de vehículos, embarcaciones y aeronaves

- Las empresas o las personas naturales dedicadas a la actividad de la construcción e inmobiliaria.

- Los Bingos, hipódromos y sus agendas, y otros similares.

- Las empresas que permitan que, mediante sus programas y sistemas de informática, se realicen operaciones sospechosas.

Las personas naturales y jurídicas que se dediquen a:

- La compra y venta de divisas.

- El comercio de antigüedades.

- El comercio de joyas, metales y piedras preciosas, monedas, objetos de arte y sellos postales. 
- Los préstamos y empeño

- Las personas jurídicas o naturales que reciban donaciones o aportes de terceros.

- Los gestores de intereses en la administración pública, según la Ley $\mathrm{N}^{\circ} 28024$

- Las organizaciones e instituciones públicas receptoras de fondos que no provengan del erario nacional.

\section{INSTRUMENTOS Y CONVENIOS INTERNACIONALES}

a. Convención contra el Tráfico Ilícito de Estupefacciones y Sustancias Psicotrópicas (aprobada por las Naciones Unidas 1988)

- La tipificación del delito de lavado de activos recomendada estaba vinculada únicamente al delito de tráfico ilícito de drogas - TID.

- Se impuso a los Estados Parte, la obligación de sancionar penalmente esta conducta

b. Las Reglas y Prácticas de Control de las Operaciones Bancarias (elaborado por el Comité de Basilea diciembre de 1988

- Se emite declaración de principios anti lavado, e insta a los bancos y entidades financieras a tomar medidas para evitar que sean utilizados para lavado de activos.

c. Convención Europea sobre Blanqueado, Rastreo, Embargo y Confiscación de los Productos del Crimen (aprobada por el Consejo de Europa en noviembre de 1990)

- Se considera como delito previo o generador del delito de lavado de activos a cualquier delito, comprendiendo a las conductas imprudentes.

d. Normativa de la Unión Europea - Directiva 91/308/CEE (elaborado por la Comunidad Europea en 1991)

- Relativa a la prevención de la utilización del sistema financiero para el lavado de activos.
- Crear legislación penal que permita cumplir las obligaciones impuestas por la Convención de Viena y el Consejo de Europa.

e) Actividades del Grupo de Acción Financiera Internacional - GAFI (organismo intergubernamental creado en diciembre de 1988)

- Propósito = elaborar y promover medidas para combatir el lavado de activos.

- Pretende establecer estándares internacionales (da recomendaciones)

- En 1990 redactó 40 recomendaciones, siendo aumentadas a 48 , que constituyen el marco básico de lucha contra el lavado de activos, concebida para una aplicación universal.

f) Comisión Interamericana para el Control del Abuso de Drogas - CICAD (elaborado por la Comunidad Europea en 1991)

En 1992, creó el Reglamento Modelo Americano sobre delitos de lavado de dinero, que contiene las conductas que deben ser tipificadas penalmente, decomiso, comunicación de conductas sospechosas

\section{ACCIONES INTERNACIONALES}

La comunidad internacional ha diseñado una política global contra el lavado de activos para adoptar estándares internacionales y normas uniformes, desarrollar instrumentos jurídicos de cooperación internacional a través de la suscripción de acuerdos con otros Estados para facilitar el intercambio de pruebas y la colaboración judicial, adoptar mecanismos para la congelación de los fondos de las organizaciones criminales y terroristas y la creación de unidades de inteligencia financiera (UIF) para centralizar el análisis de la información y de las transacciones financieras y económicas, inusuales y sospechosas. 
El Grupo de Acción Financiera Internacional (GAFI)

\section{RECOMENDACIONES DEL GAFI: PO- LITICA GLOBAL BASADO EN PRIN- CIPIOS}

- Adopción de estándares internacionales y normas uniformes sobre el lavado de activos proveniente de los delitos graves, como un delito autónomo.

- Desarrollar instrumentos jurídicos de cooperación internacional a través de la suscripción de acuerdos con otros Estados para facilitar el intercambio de pruebas, la colaboración judicial y la extradición.

- A la fecha el Perú ha sido evaluado satisfactoriamente, al haber cumplido la mayor parte de las Recomendaciones, traducidas en la promulgación de la Ley de Lavado de Activos, la creación de la Unidad de Inteligencia Financiera, entre otras.

\section{El Papel de la Auditoría Externa}

Los sujetos obligados, que de acuerdo a la legislación nacional deben someterse a auditorías externas, deben contratar auditores externos.

El Informe especial, no es complementario al informe financiero anual.

La Revisión debe efectuarla otra empresa auditora o un equipo distinto al de la auditoría financiera, según lo establezca el Reglamento. Normas de auditoría aplicables al lavado de activos.

\section{NORMAS DE AUDITORÍA APLICA- BLES AL LAVADO DE ACTIVOS}

Normas Internacionales de Auditoria para trabajos distintos a una auditoria - NISA 4400 (que reemplaza a la anterior sección
920), que forma parte del Manual Internacional de Pronunciamientos de Auditoria y Aseguramiento aprobado por la Junta de Decanos de Colegios de Contadores Públicos del Perú, que establece que el informe para este tipo de trabajos que se debe emitir es de procedimientos acordados, cuyas conclusiones son la exposición de hallazgos y que no implica la emisión de certidumbre.

\section{Objetivos:}

- Expresar una opinión sobre los estados financieros.

- Proporcionar seguridad razonable de la correcta presentación de los estados financieros.

- Opinión basada en evidencia de auditoría.

\section{CONCLUSIONES}

1. El Sistema Bancario es el sector estratégico que utilizan para el lavado de dinero, ya que la gran variedad de transacciones que se pueden realizar facilitan la labor de la etapa de "colocación"

2. Si bien es cierto que en nuestro país no se clasifica formalmente a las entidades financieras en su posible nivel de participación en las operaciones de lavado de dinero, para las labores de inteligencia los investigadores fiscales establecen categorías funcionales en función de los antecedentes de estas empresas que configuran el nivel de riesgo de que efectivamente tengan participación, es decir aquellas que han estado involucradas en este tipo de actividades a través de empleados que actuaron por iniciativa personal, es necesario que se les capacite a los funcionarios y empleados con respecto a la aplicación de las normas legales concernientes a este tema. 
3. En los últimos años se ha incrementado el interés en la lucha contra el lavado de activos, en ella, las autoridades y los organismos internacionales están tomando medidas para hacer más efectivo el control del lavado, pero esas medidas son lentas, incompletas y no abarcan a toda la industria.

4. La globalización y la tecnología le permiten a las organizaciones criminales tener más herramientas para sus objetivos, mejorando la comunicación y permitiéndoles difundir sus transacciones a través de un mayor número de países, obstaculizando las investigaciones.

5. El lavado de Activos es considerado uno de los mayores flagelos que aqueja al mundo.

6. La responsabilidad por el control del Lavado de Activos recae en todos los funcionarios de una Institución Financiera.

7. El lavado de activos se ha convertido en un mecanismo fundamental de financiación internacional para actividades ilícitas. La reducción de este problema se ha convertido en principal objetivo de los gobiernos como parte de sus guerras contra el terrorismo y el uso indebido de drogas.

8. El control del Lavado de Activos debe realizarse sobre cualquier tipo de operación.

\section{RECOMENDACIONES}

1. Se deben fortalecer los organismos de control internacionales, para que estos puedan establecer medidas de protección eficaces para los países. Estos deben aumentar el intercambio de información relativa a las transacciones, personas o empresas sospechosas.

2. Aumentar el control sobre los movimientos de capitales y llevar un registro detallado, sobre las personas involucradas en dichas transacciones, tanto en entidades financieras, compañías de fachada y venta de bienes e inmuebles.

3. Realizar revisiones sistemáticas por parte de las entidades financieras de sus cuentas corresponsales con bancos extranjeros, reforzar la supervisión de movimientos sospechosos, mediante la implementación de revisiones regulares de las transferencias telegráficas o electrónicas y proporcionando entrenamiento al personal para que reconozcan las conductas impropias de los bancos extranjeros.

4. Enfatizar la importancia de la supervisión minuciosa de áreas como los paraísos fiscales, ya que mientras estos continúen propiciando ingresos de capitales sin investigación ni control, la efectividad de cualquier medida mundial contra el lavado de dinero será ineficaz.

5. Realizar campañas públicas en los medios masivos de comunicación, para concientizar a los ciudadanos de los daños económicos, políticos y sociales que genera el lavado de activos.

\section{REFERENCIAS BIBLIOGRÁFICAS}

1. ÁNGEL, José. Fraude fiscal y lavado de capitales. En: Revista Electrónica Semestral de Políticas Públicas en Materias Penales [En línea], (Julio 2009), Vol. 2, No 7, [citado el 10 de abril de 2011], p 1-19, ISSN: 07183399.

2. BECHT, Marco; ENRIQUES, Luca y KOROM, Veronika. Centers and the cost of branching. En: Journal of Corporate Law Studies [En línea], (Abril 2009), Vol. 9, No 1, [citado el 16 de abril 2011], p171-199,

3. CINDORI, Sonja. The moneylaundering prevention system. En: Financial Theory \& Practice [En línea], (2007), [citado el 12 de mayo 2011]. 